\title{
Out-of-School Time-Use Portfolios and Taiwanese Children’s Reading Achievement ${ }^{*}$
}

\author{
Su-Yen Chen, Hsing-Yu Chang \\ National Tsing-Hua University, Hsinchu City, Taiwan
}

\begin{abstract}
In this study, we investigated how Taiwanese 5th graders spent time on six out-of-school activities, including homework, after-school private programs, print-based reading, online reading, online films/games, and TV, and documented time-use portfolios and their reading achievement. Using a cluster analysis, we identified five distinct groups of students that shared similar patterns of time use for the six activities to provide a more complete picture on what students do outside of school. The findings suggested that Group 1, which invested more time in homework and in overall academic activities, demonstrated good performance on both Chinese character recognition and reading comprehension. Moreover, the performance of Group 2 indicated that those spending a favorable ratio of time on reading seemed to be equally successful despite their spending relatively less time on homework and academic activities in total than other groups. Finally, Group 4 and especially Group 5, which spent too much time on online films/games and overall entertainment activities tended to performed more poorly than the other groups.
\end{abstract}

Keywords: children, Taiwan, reading achievement, time use, portfolios

\section{Introduction}

In a review study on how children and adolescents throughout the world spend their time, Larson and Verma (1999) expanded economists' conception of time as a unit of "human capital" and proposed that the youth's time use is a resource that enables them to develop a much wider range of faculties besides economic ones, including skills, knowledge, and experiences. Although researchers have long been concerned about youth's daily activities, such studies are scarce, and most have focused on a single activity (Ben-Arieh \& Ofir, 2002; Zick, 2010); even fewer studies have linked time spent on various activities to students' academic achievement.

Nevertheless, a few previous studies have shed some light on this topic. For example, in an attempt to understand some of the reasons for the higher academic achievement of Chinese and Japanese children compared to children in the United States (U.S.), Stevenson et al. (1990) found that elementary school children from different cultures allocated their time in different ways, and the differences appeared to offer one explanation for the gaps in achievement in reading or mathematics. Children from Taiwan and Japan spent more time on out-of-school academic activities than their U.S. counterparts. Time estimates collected from

\footnotetext{
*Acknowledgment: The authors would like to thank the National Science Council of the Republic of China for financially supporting this research under Contract No. NSC 100-2420-H-007-001-MY3.

Su-Yen Chen, Ph.D., professor, Institute of Learning Sciences, National Tsing-Hua University.

Hsing-Yu Chang, M.A., research assistant, Institute of Learning Sciences, National Tsing-Hua University.
} 
mothers during interviews showed that U.S. 5th graders spent 0.6 hours per day on homework, as compared with 0.9 hours for Japanese and 1.8 hours for Taiwanese 5th graders. Similarly, U.S. 5th graders spent 39 minutes per day on reading, as compared with 41 minutes for Taiwanese and 55 minutes for Japanese 5th graders. For non-academic activities, U.S. 5th graders watched TV for 2.0 hours per day, as compared with 2.3 hours for Japanese and 1.5 hours for Taiwanese 5th graders. Another classic example is Anderson, Wilson, and Fielding's (1988) intensive study, which used activity diaries to collect information on the amount of time American 5th graders spent on various out-of-school activities and examined the relationships between time use and different activities and reading achievement. They found that reading books was the best predictor of several measures of reading achievement, including gains in reading achievement between 2nd and 5th graders; also, the amount of time spent on homework had a significant influence on growth in reading comprehension, but watching TV had a small negative relationship with measures of reading proficiency.

In addition to the out-of-school activities mentioned above, the phenomenon of students attending after-school private programs and its linkage to students' academic achievement have been attracting increasing researchers' attention in East Asian countries (Bae, H. Oh, Kim, Lee \& B. Oh, 2010; Bray, 2014; Chen \& Lu, 2009; Kwok, 2004; Lee, Yang, \& Lin, 2012; Song, Park, \& Sang, 2013; Tse, 2014). Similarly, as a pervasive daily activity for youth nowadays, online practice, as well as its association with academic achievement, is emerging as a research trend among Taiwanese researchers (e.g., Chen \& Fu, 2009; Chen \& Lu, 2009; Lee \& $\mathrm{Wu}, 2014)$. In line with this trend, with data collected from activity diaries, this study used the precise time amount as the indicator for level of involvement on activities, or level of investment upon learning-oriented activities specifically, among Taiwanese 5th graders. The present study aimed to create portraits of time use for various out-of-school activities, including homework, after-school private programs, print-based reading, online reading, online films/games, and TV, and to investigate the linkage between time-use portfolios and reading achievement from a holistic perspective. For the purpose of this study, we first review the relationships between involvement in these activities and academic achievement, followed by studies identifying naturally occurring portfolios for similar patterns of activities involvement to examine how the memberships are associated with academic success.

\section{Out-of-School Activities and Academic Achievement}

The relationships of doing homework, attending after-school private programs, and engaging in print-based reading with students' academic achievement have been well explored in extant literature. Many studies have addressed a single activity, but only a few studies have examined multiple activities at the same time, including watching TV or playing online games. Even though most studies have used survey questions to indicate frequency for the sake of convenience rather than utilizing activity diaries to collect more accurate time estimates, these prior studies still contribute to our understanding of out-of-school activity engagement and academic achievement.

Regarding homework, in a meta-analysis conducted to determine whether homework improves academic achievement, Cooper, Robinson, and Patall (2006) examined studies conducted in the U.S. from 1987 to 2003. They found generally consistent evidence that homework has a positive influence on achievement. A stronger correlation was revealed for grades 7-12 than for grade K-6, but there was no strong evidence for an association between the homework achievement link and the subject matter. Trautwein (2007), however, differentiated between time spent on homework and homework effort. The results of his study indicated that while homework 
effort on mathematics was positively related to mathematics achievement and achievement gains, homework time on mathematics was not related, or was negatively related to mathematics effort. In other words, if a student reports spending a lot of time on his/her homework, this is not necessarily a sign of great effort, but instead may reflect problems of motivation or concentration. This perspective offers an important insight, considering that most studies take it for granted that more time means more effort, which then leads to higher achievement.

Regarding after-school private programs, in a review study on the impact of shadow education on student academic achievement in East Asia, Bray (2014) defined private supplementary tutoring in his study as that which is provided in exchange for a fee, is provided in addition to regular schooling, and addresses academic subjects. Bray found the research findings to be inconclusive and proposed that the qualities of the instructors and the motivations of the students should be taken into account for future research. Tse (2014) used data from the Progress in International Reading Literacy Study (PIRLS) 2011 to examine the relationship between attending after-school private programs and 9-year-old children's reading attainment in Hong Kong. He found that even though over $75.5 \%$ of the children who received after-school private programs thought their Chinese competence had improved as a consequence of being tutored, the scores of reading comprehension of the students who received private tutoring on Chinese or Chinese and other subjects were significantly lower than those of students who did not. The researcher suggested that the government should give guidance to parents about selecting good private after-school programs.

Regarding print-based reading, Mol and Bus (2011) conducted a meta-analysis on 99 studies of print exposure, from infancy to early adulthood, and found moderate to strong correlations between leisure time reading and reading-related achievement, including oral language, spelling, word recognition, and reading comprehension. The researchers suggested an upward spiral of causality: Children who are more successful readers read more; because of more print exposure, their reading achievement improved more with each year of education. More importantly, they also found that the basic reading skills of children in primary and middle school with lower ability levels were more strongly related to leisure time reading than was the case for higher ability readers. Chen and Fang (2013) corroborated findings from previous studies that Taiwanese college students' print exposure is significantly associated with their Chinese character recognition and reading comprehension. In a later study, they found similar results for Taiwanese 5th graders (Chen \& Fang, 2014). In addition to the more traditional print-based reading, the association between online reading and reading achievement has recently been explored. Using data from the Programme for International Student Assessment (PISA) 2009, Lee and Wu (2012) expanded the notion of reading to create an index of engagement in online reading activities, including reading e-mails, chatting online, reading online news, using an online dictionary or encyclopedia, searching for online information to learn about a particular topic, participating in online group discussion or forums, and searching for practical information online, based on Leu, Kinzer, Coiro, and Cammack's (2004) definition of new literacy. The researchers examined the relationships among students' attitude toward computers, confidence in high-level information and communications technology (ICT) tasks, access to ICT facilities at home or school, online reading engagement, and students' reading attainment. They found that reading comprehension scores improved with better attitude, confidence, and access at home, as long as the effect was mediated through engagement in online reading activities, but ICT access at home had a direct and negative impact on reading attainment. 
Regarding studies conducted to explore relationships between multiple activities and academic achievement, Cooper, Valentine, Nye, and Lindsay (1999) investigated the linkage of five types of after-school activities, including homework, TV, extracurricular activities, other types of structured groups, and jobs, to standardized test scores and class grades, with a sample of 424 U.S. students in grades 6 through 12 . The results indicated that all five activities were significantly correlated with both achievement measures; among them, the amount of homework finished had a positive association with achievement measures, whereas time spent on watching TV had a negative association. Even after the student's gender, grade level, ethnicity, free-lunch eligibility, and level of adult supervision after school were statistically controlled, the amount of homework finished still contributed to the teacher-assigned grade, while time spent on watching TV became a statistically insignificant factor. In another study, Schreiber and Chambers (2002) used data from National Education Longitudinal Study (NELS) 1988 conducted by the U.S. Department of Education on 8th graders and also the follow-up data as 10th graders. They grouped all after-school activities into six categories: (a) in-school academic organized; (b) in-school non-academic organized; (c) out-of-school non-academic organized; (d) out-of-school non-academic, non-organized activities other than TV; (e) out-of-school non-academic, non-organized-TV; and (f) out-of-school academic, non-organized-homework. Concerning the relationships between homework and TV and achievement on four subject areas including reading, mathematics, science, and geography/history, the findings revealed that when gender, socioeconomic status, and all six categories of activities were taken into consideration, both homework and watching TV were found to be significant predictors for achievement of all four subject areas, among other predictors. Homework was found to be positively related to achievement, while watching TV was found to be negatively related to achievement.

For Taiwanese adolescents, Chen and Lu (2009) used national data from the Taiwan Educational Panel Survey (TEPS) 2005 on 11th graders and also their follow-up data as 12th graders, and investigated the linkage of nine after-school activities to their educational achievement. These nine after-school activities were: homework, academic-enrichment programs provided by the school, private cram schools, school-based extracurricular activity, TV or videos, sports engagement, extracurricular reading, Internet games, and part-time employment. The findings indicated that TV or videos, Internet games, and part-time employment were negatively correlated with academic achievement in the zero-order correlation, while the other six after-school activities were positively correlated. Moreover, even when gender, father's educational level, mother's educational level, family income, and educational achievement in the 11th grade were controlled, time spent on homework, academic-enrichment programs provided by the school, private cram schools, and extracurricular reading still were found to make a positive contribution to educational achievement in the 12th grade, while watching TV and part-time employment negatively contributed educational achievement in the 12th grade. In another study, Chen and Fu (2009) used data from the Taiwan Youth Project (TYP) and examined the linkages between online activities and Taiwanese 9th graders' academic achievement. They found that using the Internet to search for information, to play games, and to chat and socialize were all significant predictors of academic achievement. While using the Internet to search for information was positively linked, using the Internet both to play games and to chat or socialize was negatively linked to the academic achievement. Moreover, when they separated the sample according to respondents' gender, using the Internet to search for information was positively linked to academic achievement and using Internet to play games was negatively linked to academic achievement only for male students, while using Internet to chat and socialize was negatively linked to academic achievement only for female students. 
Overall, first, previous studies have suggested that homework is positively related to academic achievement, both when it is examined as a single activity and when other activities are taken into account. The positive relationship also appears to be cross-cultural, even though such a linkage has not been explored among Taiwanese elementary school students. Second, findings from the empirical study revealed the impact of after-school private programs on academic achievement to be inconclusive. Whereas Chen and Lu (2009) found that time spent on private cram schools was beneficial for the growth of Taiwanese secondary school students' academic achievement, results from Tse's (2014) study cast some doubts about a positive linkage between attending private after-school tuition and the PIRLS reading attainment of children in Hong Kong. These inconsistent findings echoed Bray's (2014) review. It is important, however, to differentiate after-school private programs for elementary school children from those for secondary school students, at least in Taiwan. While such programs aim to prepare older students to get into good high schools and colleges, activities in programs for children are more versatile and may include homework help, second language lessons, talent classes, supervised computer use, and so on (Lee et al., 2012; Stevenson et al., 1990). The association between attending these programs and academic achievement might be influenced by the goal of the program. Third, extant literature has generally concurred that leisure time print-based reading has a positive impact on academic achievement, especially on reading-related achievement, across cultures. As online activity has gradually become one of the most popular out-of-school activities for youth in modern society, online reading as a specific category of daily activity and its possible positive association with students' reading achievement has been only initially explored and awaits further investigation. Finally, it seems to be universally recognized that watching TV has a detrimental effect on academic achievement across subject areas and across cultures. Another similar type of out-of-school passive activity is online films/games, and recent studies on Taiwanese adolescents have suggested that online games also have a detrimental effect on students' academic achievement. It is not uncommon that youth who suffer from a lack of supervision might develop disordered behaviors, such as addictions to online games or TV (Lee et al., 2012).

\section{Portfolios for Similar Patterns in the Real World}

Most of the above studies used regression analysis to examine how participation in a specific out-of-school activity or multiple activities helped predict academic achievement. In the real world, however, each student spends his/her out-of-school time on a variety of activities. To provide a holistic picture of students' patterns of engagement in various activities and their linkages to academic achievement, a number of studies have used cluster analysis to identify naturally occurring profiles. Kuh, Hu, and Vesper (2000), for example, classified students into meaningful reference groups based on the activities in which students engaged during college and investigated the relationship between the memberships and desired learning outcomes. With a sample of 51,155 American college students, they generated 10 types of students and found that students typically learned what they studied and developed skills and competencies consistent with the activities to which they devoted effort. To be specific, they found the Intellect, Individualists, Scientist, Conventional, and Collegiate groups were above average in terms of gains and the Disengaged, Grind, Recreator, Socializer, and Artist groups were below average. In another study, Nelson and Gastic (2009) used data collected from the U.S. Educational Longitudinal Study (ELS) 2002 to examine how out-of-school time activity portfolios of 6,338 high school students correlated with academic achievement. The cluster analysis yielded five distinct profiles based on 15 out-of-school activities. The results indicated that students differed significantly in terms of 
academic success on the basis of their portfolio type. To be specific, the Study portfolio has a significantly higher percentage of students in the highest achievement quartile than any other group; in contrast, the percentage of students in the highest academic achievement quartile in the Unstructured Recreation group was significantly lower than the percentages of students in this quartile that were in the Employed or Study groups. In general, researchers have recognized the value of this kind of study as being a useful way to describe the multiple microcosms of out-of-school life and as providing a heuristic framework for educators to identify student groups that perform better than others in certain areas and those who participate in activities that do not attain similar levels of desirable progress.

Based on the previous literature, the purpose of this study is threefold:

1. How do Taiwanese 5th graders spend time on various out-of-school activities?

2. What are the patterns of time use in terms of six categories of out-of-school activity, including homework, after-school private programs, print-based reading, online reading, online films/games, and TV?

3. How does time use in each activity portfolio correlate with 5th graders' two measures of reading achievement: Chinese character recognition and reading comprehension?

\section{Methods}

\section{Sample}

The data for this study were collected as part of a larger study dealing with instrument development on print exposure for Taiwanese 5th graders. The sample consisted of 318 5th graders (153 boys and 165 girls) in 11 classes from three elementary schools in Northern Taiwan. As two measures of reading achievement, all students were invited to record time spent on writing in a daily activity diary for seven school days and three non-school days, and take the Chinese Character Recognition Test and the Reading Comprehension Test. After close examination, we deleted incomplete and unreasonable data collected from the daily activity diary, and the valid sample for this study consisted of 295 5th graders (51\% boys and $49 \%$ girls).

\section{Research Instruments}

Daily activity diaries. We developed our instrument for collecting daily activity data based on Anderson et al. (1988) and Allen, Cipielewski, and Stanovich's (1992) forms of diaries, which proposed including nearly exhaustive and mutually exclusive activity categories. The content of the original categories reflected cultural differences, however, and so we revised them for modern Taiwanese readers as follows: attending school; going to after-school private programs; walking or taking transportation; doing homework; eating; doing chores; playing; watching TV; doing teacher-assigned extracurricular reading; reading comics for pleasure; reading short stories or articles for pleasure; reading fiction for pleasure; reading non-fiction for pleasure; playing online games; watching online films; browsing online information; engaging in online social networking (e.g., Facebook); engaging in Internet reading (online fiction, non-fiction, short stories, articles, comics, and magazines); sleeping; and others. Although we paid special attention to reading, we still made an effort to obtain a comprehensive assessment of Taiwanese children's out-of-school activities. To generate a solid and complete picture on Taiwanese 5th graders' out-of-school time use, we collected data for seven school days and three non-school days. We used a graphical layout, in which extended across each row were time lines ranging from 3:00 p.m. to midnight for school days, and from 6:00 a.m. to midnight for non-school days, divided into quarter hours. Students filled out activity sheets each school day, recording their previous day's or days' 
activities. The respondents were instructed to date each sheet and to account for all time blocks. Therefore, the total amount of minutes spent after school for seven school days was 540 ( 9 hours per day) $\times 7=3,780$ minutes, and the total number of minutes spent for three non-school days was 1,080 (18 hours per day) $\times 3=3,240$ minutes. The total amount of minutes collected for the 10 days was 7,020 minutes, and the average number of minutes spent per day was 702 minutes. The daily activity diaries were analyzed by summing the number of minutes in each activity category across 10 days and then dividing by 10 to get the average number of minutes spent per day for each particular activity.

Chinese Character Recognition Test. The participants completed the Chinese Character Recognition Test developed by Hung, Wang, Chang, H. F. Chen, and Q. S. Chen (2006) for elementary and junior high school students. For the purpose of this study, the version designed for 3rd through 9th graders was used. This test consisted of 40 Chinese characters, which belonged to three frequency levels: 19 words from Level 1, which included those characters occupying ranks above 2,000 in the National Institute for Compilation and Translation (NICT) character-frequency norm; 15 words from Level 2, which included those characters occupying ranks 2,000 to 3,500, with three words for every 300 sublevel; and six words from Level 3, which included those characters occupying ranks 3,500 to 5,021, with three words for every 700 sublevel (Wang, Hung, Chang, \& Chen, 2008). The participants were first asked to respond to each of the test characters by writing down both its pronunciation, using the Mandarin Phonetic Alphabet, and using the character to compose a word or phrase. Then, the number of characters that the participants knew was estimated based on a list provided by the test, with a score ranging from 0 to 5,021. The Cronbach's alpha for 5 th graders was 0.91 , and the split-half reliability score was 0.93 .

Reading Comprehension Test. The participants also completed the Reading Comprehension Test developed by Ko and Zhan (2006) for 2nd through 6th graders, with a sample of 2,712. For the purpose of this study, the 5-A version designed for 5th graders was used. The participants had 25 minutes to read an essay and answer 31 comprehension questions. Among them, 12 questions were related to the usage of polysemous words, six to proposition assembly, four to sentence-level comprehension, and nine to passage-level comprehension. Scores ranged from 0 to 31. The Cronbach's alpha for this specific version was 0.91 .

\section{Results}

As mentioned above, we used the average number of minutes spent per day (across seven school days and three non-school days) to present the daily time use for elementary school students' activities, and, for the purpose of this study, not all activities were included in the analysis. Table 1 shows the number, the minimal time spent, the maximum time spent, the means, and the standard deviations respondents reported spending per day regarding 13 activities. Among them, 70.97 minutes were spent on homework, 58.62 minutes on after-school private programs, 50.32 minutes on watching TV, and 23.55 minutes on online games, on average. In addition to these four activities, Taiwanese 5th graders also engaged in the following activities within 10 minutes per day, on average, ranging from spending the most to the least: reading fiction, watching online films, teacher-assigned reading, reading comics, browsing online information, reading non-fiction, online social networking, reading short stories or articles, and online reading, respectively. It is interesting to note that for every activity, at least one student reported not spending any time across the 10 days, which shown as 0 minute for the minimal time spent. Regarding homework, considering some of the children did their homework in after-school private programs that provided homework help, an indication on the daily activity diaries for not 
spending time on homework is reasonable. Moreover, based on the previous literature and for the convenience of analysis, this study further merged the 13 activities into six categories: homework, after-school private programs, print-based reading (e.g., comics, short stories or articles, fiction, non-fiction, and teacher-assigned extracurricular reading), online reading (browning information, social networking, and Internet reading), online films/games, and TV. The amount of time spent on each category was added for every student, and then the six scores were used in subsequent steps of the analysis.

Table 1

Descriptive Information for Research Variables

\begin{tabular}{llllrrr}
\hline & & $N$ & Min & Max & Mean & \multicolumn{1}{l}{$S D$} \\
\hline \multirow{4}{*}{ Activities } & Homework & 295 & 0 & 211.49 & 70.97 & 42.76 \\
& After-school private programs & 295 & 0 & 180.00 & 58.62 & 44.05 \\
& TV & 295 & 0 & 202.50 & 50.32 & 45.64 \\
\hline \multirow{5}{*}{ Print-based reading } & Comic books & 295 & 0 & 105.00 & 5.65 & 12.40 \\
& Short stories or articles & 295 & 0 & 57.06 & 3.34 & 8.63 \\
& Fiction & 295 & 0 & 107.96 & 7.67 & 15.17 \\
& Non-fiction & 295 & 0 & 109.50 & 3.51 & 10.24 \\
& Teacher-assigned reading & 295 & 0 & 58.50 & 6.52 & 10.70 \\
\hline \multirow{5}{*}{ Online reading } & Browsing information & 295 & 0 & 66.02 & 4.07 & 8.51 \\
& Social networking & 295 & 0 & 65.96 & 3.51 & 9.31 \\
& Internet reading & 295 & 0 & 84.05 & 3.23 & 7.98 \\
\hline \multirow{2}{*}{ Online films/games } & Online games & 295 & 0 & 245.99 & 23.55 & 40.78 \\
& Film watching & 295 & 0 & 93.00 & 7.06 & 14.76 \\
\hline
\end{tabular}

We used a cluster analysis to identify groupings of students that shared similar patterns of time use for the six activities, because cluster analysis aims to maximize both between-cluster heterogeneity and within-cluster homogeneity. K-mean cluster analysis was employed, in contrast to hierarchical cluster analysis, because the sample size of the present study was around 300. Five-cluster solution was chosen because the patterns of time use differed from each other, yet the number of groups was not so great that the distinctions between groups would be trivial or meaningless, a principle suggested by Kuh et al. (2000). In other words, we generated five profiles of students based on their out-of-school time use on the six activities, namely, homework, after-school private programs, print-based reading, online reading, online films/games, and TV watching. Table 2 presents the mean time use for the six after-school activities for each of the profile groups. Significant mean differences across profiles on the six activities were found based on $F$ values, indicating how each group spent its time. To depict these five portfolios more accurately and in depth, in the following discussion, we not only pay attention to time use on each of the six activities, but also discuss these activities in pairs, namely, homework and after-school private programs as academic activities, print-based reading and online reading as reading activities, and TV and online films/games as unsupervised activities.

Group 1 ( $N=71$ ), which consisted of around one quarter of the students, were those who spent the highest average amount of time among the five profile groups not only on homework (for more than two hours per day), but also on overall academic activities, defined by combining time spent on homework and on after-school private programs, for a total of more than three hours per day. At the same time, they spent the least amount of time on both online films/games and on TV, the unsupervised activities. 
Group $2(N=119)$ had the most students among the five profile groups and consisted of $40 \%$ of the students. Those in this group spent around 1.5 hours per day on academic activities. They are also possessed the distinguishing features of spending the greatest amount of time among five profile groups not only on print-based reading, for 35 minutes per day, but also on reading activities in total, for 48 minutes per day.

Group $3(N=72)$ also consisted of around one quarter of the students like Group 1; Group 3 students spent the most time in after-school private programs, around 1.5 hours per day. Students in this group spent around 2.5 hours on academic activities, on average. In addition, Group 3 had the second highest average TV watching time among the five profile groups, for approximately 1.5 hours per day.

Group $4(N=12)$ had the fewest students of all the five profile groups, with only $4 \%$ of all students, and only one female student. Similar to Group 3, their average time spent on academic activities was around 2.5 hours. They spent the most time on online films/games among the five profile groups, for almost three hours per day, indicating a possible addiction. They also spent the least amount of time on reading activities, for less than 20 minutes per day.

Finally, Group 5 ( $N=21)$, consisted of $7 \%$ of the students and also had more male students than female students. These are the students who used most of their time on unsupervised activities, including online films/games and TV watching. Their average time spent on these activities was nearly four hours per day.

Table 2

Means (SDs) of Minutes Spent per Day, on Average, for the Six Out-of-School Activities By Profile Group and Results of Analysis of Variance (ANOVA)

\begin{tabular}{|c|c|c|c|c|c|c|c|}
\hline & & \multicolumn{2}{|c|}{ Academic activities } & \multicolumn{2}{|c|}{ Reading activities } & \multicolumn{2}{|c|}{ Unsupervised activities } \\
\hline & & Homework & $\begin{array}{l}\text { After-school } \\
\text { private } \\
\text { programs }\end{array}$ & $\begin{array}{l}\text { Print-based } \\
\text { reading }\end{array}$ & Online reading & $\begin{array}{l}\text { Online films/ } \\
\text { games }\end{array}$ & TV \\
\hline Group 1 & $\begin{array}{l}N=71(24 \%) ; \\
M=35 ; F=35\end{array}$ & $126.53(32.62)$ & $66.04(40.62)$ & 24.72 (25.91) & $8.30(13.69)$ & $11.93(17.45)$ & $23.22(24.17)$ \\
\hline Group 2 & $\begin{array}{l}N=119(40 \%) \\
M=53 ; F=66\end{array}$ & $58.61(25.02)$ & 33.30 (28.13) & 35.46 (29.76) & $12.40(16.56)$ & $18.54(20.83)$ & $32.44(26.29)$ \\
\hline Group 3 & $\begin{array}{l}N=72(24 \%) ; \\
M=35 ; F=36\end{array}$ & $42.40(27.64)$ & 98.34 (37.97) & 21.27 (26.07) & 8.21 (12.19) & $22.00(20.30)$ & $89.39(45.35)$ \\
\hline Group 4 & $\begin{array}{l}N=12(4 \%) \\
M=11 ; F=1\end{array}$ & $63.71(34.71)$ & $73.71(47.07)$ & 11.40 (17.18) & $6.38(9.61)$ & $168.60(50.94)$ & $38.72(31.80)$ \\
\hline Group 5 & $\begin{array}{l}N=21(7 \%) ; \\
M=15 ; F=6\end{array}$ & $55.27(31.47)$ & $32.30(34.43)$ & $10.91(18.67)$ & $21.73(27.24)$ & $112.85(41.73)$ & $115.99(45.07)$ \\
\hline$F(4,290)$ & & $92.90^{* * *}$ & $42.59^{* * *}$ & $6.76^{* * *}$ & $4.00^{* *}$ & $183.54^{* * *}$ & $66.17^{* * *}$ \\
\hline
\end{tabular}

Notes. ${ }^{*} p<0.05,{ }^{* *} p<0.01$, and ${ }^{* * *} p<0.001$.

Table 3 shows the means and standard deviations for scores on the Chinese Character Recognition Test and Reading Comprehension Test according to the five profiles, as well as the results of the ANOVA and post-hoc pairwise contrasts. According to Table 3, for the Chinese Character Recognition Test, the post-hoc pairwise contrast showed that Group 1's vocabulary capacities were significantly better than those of Group 5, indicating that those who invested more time in homework, around two hours per day, and in overall academic activities, around three hours per day, tended to perform better than those who spent the highest amount of time on TV and online films/games, each consuming two hours of their out-of-school free time per day. Moreover, Group 2 had not only the highest scores on the Chinese character recognition among all profiles of students, but also significantly higher scores than Groups 4 and 5, suggesting that those who were characterized as avid 
readers seemed to perform better than students who either had a tendency of TV addiction (watching almost three hours per day) or spent much time engaging in unsupervised entertainment-oriented activities (for four hours per day). It is important to note that, actually, Group 2 spent much less time on homework and on after-school private programs than Group 1, about only one half of the amount, but their performance on the Chinese Character Recognition Test was a little better or at least as good as that of Group 1.

Table 3

Number, Minimal and Maximum Scores, Means and Standard Deviations for Chinese Character Recognition and Reading Comprehension By Each of the Five Group Profiles, and Results of the ANOVA as Well as the Post-Hoc Pairwise Contrasts

\begin{tabular}{|c|c|c|c|c|c|c|c|c|}
\hline & & Group 1 & Group 2 & Group 3 & Group 4 & Group 5 & $F$ & $\begin{array}{l}\text { Post-hoc } \\
\text { pairwise } \\
\text { contrasts }\end{array}$ \\
\hline \multirow{5}{*}{$\begin{array}{l}\text { Chinese character } \\
\text { recognition }\end{array}$} & $N$ & 68 & 117 & 72 & 12 & 21 & \multirow{5}{*}{$6.13^{* * *}$} & \multirow{5}{*}{$\begin{array}{l}1>5^{*} \\
2>5^{* *} \\
2>4^{*}\end{array}$} \\
\hline & Min & 1,256 & 1,918 & 1,369 & 1,623 & 1,383 & & \\
\hline & Max & 4,801 & 4,941 & 4,911 & 3,993 & 4,301 & & \\
\hline & Mean & 3,528.71 & $3,592.47$ & $3,450.99$ & 2,841.17 & $2,871.57$ & & \\
\hline & $S D$ & 739.39 & 727.49 & 817.65 & 745.39 & 836.46 & & \\
\hline \multirow{5}{*}{$\begin{array}{l}\text { Reading } \\
\text { comprehension }\end{array}$} & $N$ & 70 & 119 & 71 & 12 & 21 & \multirow{5}{*}{$5.96^{* * *}$} & \multirow{5}{*}{$\begin{array}{l}1>5^{* *} \\
2>5^{* *} \\
3>5^{*}\end{array}$} \\
\hline & Min & 10 & 7 & 13 & 16 & 10 & & \\
\hline & Max & 30 & 31 & 30 & 27 & 26 & & \\
\hline & Mean & 23.40 & 23.14 & 22.34 & 20.25 & 18.67 & & \\
\hline & $S D$ & 4.50 & 4.86 & 3.88 & 3.55 & 4.28 & & \\
\hline
\end{tabular}

Notes. ${ }^{*} p<0.05,{ }^{* *} p<0.01$, and ${ }^{* * *} p<0.001$.

For the Reading Comprehension Test, the mean scores for each profile from the highest to the lowest corresponded to the group order, from Group 1 to Group 5. According to the post-hoc pairwise contrasts, Groups 1, 2, and 3 all had significantly higher scores than Group 5. When we examined the time-use patterns, we found that Groups 1, 3, and 4 all spent more than 2.5 hours on academic activities, while Groups 2 and 5 each spent only around 1.5 hours on the same activities, though at the same time, Group 2 spent the most time on reading among the five groups. In contrast, Groups 1, 2, and 3 spent less than two hours on unsupervised entertainment-oriented activities, whereas Groups 4 and 5 spent around 3.5 hours or more on them. Overall, the results provided more evidence to support that student profiles, such as Groups 1, 2, and 3, investing more time in learning opportunities and spending less time on entertainment tend to perform better than the profile spending a lot of time on entertainment and a little time on academic activities, such as Group 5.

\section{Discussion and Conclusion}

In this study, we investigated how Taiwanese 5th graders spent time on various out-of-school activities and documented their time-use portfolios and reading achievement. This study differed from other studies on out-of-school activities and academic achievement in that it collected the precise amount of time spent on activities for seven school days and three non-school days with daily activity diaries, rather than using limited survey questions to get an overall frequency or time amount; at the same time, this study used the precise time spent on various activities to identify out-of-school time-use profiles, rather than looking at each activity separately, to provide a more complete picture of what students do outside of school.

According to Stevenson et al. (1990), Taiwanese mothers estimated that their 5th graders spent 1.8 hours 
per day on homework, 41 minutes on reading, and 1.5 hours on TV. Thirty years later, Taiwanese 5th graders in our study reported in their out-of-school daily activity diaries that, on average, they spent 70 minutes per day on homework and one hour on after-school private programs; 27 minutes on print-based reading and 11 minutes on online reading; and 50 minutes on TV, as well as 30 minutes on online films/games. The results appear to reflect a change in social structure, in that many busy parents have begun to send their children to private after-school programs, and also a change in media format, in that some print-based reading might be replaced by online reading and some TV watching might be replaced by online films/games. Overall, how Taiwanese 5th graders are allocating their out-of-school time, however, has remained somewhat stable along the timeline.

As for patterns of time use in terms of the six categories of out-of-school activities, it is interesting to find that only Groups 4 and 5, which in total consisted of around 11\% of the students and were mostly boys, revealed an over indulging on the "not so desirable" out-of-school activities, such as watching TV and engaging in online films/games, for more than three or four hours per day. In contrast, Group 2, which consisted of as many as $40 \%$ of the students, used their time in a balanced way: one hour on homework, $1 / 2$ hour on after-school private programs, $1 / 2$ hour on print-based reading, 1/2 hour on online activities (12 minutes on online reading and 19 minutes on online film/games), and 1/2 hour on TV. Group 1, about one quarter of the students, were hard workers; they spent more than two hours on homework, plus one more hour on after-school private programs, to improve their academic competency. And for another one quarter of the students, Group 3, time use was characterized as spending 40 minutes on homework, one and 1/2 hours on after-school private programs for homework help and all kinds of talent classes, and one and 1/2 hours on TV. Since no previous study had compiled portfolios for Taiwanese children based on their out-of-school time use, one contribution of this study is to identify five distinct profiles that represent five types of students.

The linkage between activity portfolios and the two measures of reading achievement corroborates and extends results from previous studies. First, spending time on homework appeared to have had a positive effect on academic achievement, considering that Group 1, which spent as much as twice of the time amount on homework than the other profile groups, demonstrated good performance on both Chinese character recognition and reading comprehension. Specifically, their mean scores on both measures were significantly higher than Group 5's. Second, even though the positive effect of print-based reading on reading achievement has been well-established, no study has explored its importance with the method of activity portfolios. The performance of Group 2 suggested that spending a favorable ratio of time on reading seemed to yield equally successful outcomes in terms of Chinese character recognition and reading comprehension, despite their spending relatively less time on homework and academic activities in total than most other groups. Avid readers, Group 2, did as well as the hard workers, Group 1, on reading comprehension, and performed even a little better than Group 1 on Chinese character recognition. Specifically, their mean score on Chinese character recognition was significantly higher than those of Groups 4 and 5, while their mean score for reading comprehension was significantly higher than Group 5's. Third, spending too much time on online films/games and on both TV and online films/games appeared to have a negative effect on academic achievement, considering the performance of Group 4 and especially Group 5. Due to the limitation of the research method used in this study, however, the results of this study could not provide evidence to advance our understanding on the relationships of after-school private programs and online reading to reading achievement. 
Taken altogether, the findings of this study indicated that students spending more time on homework, on academic activities in total, and on reading, and at the same time spending a reasonable amount of time on entertainment, such as watching TV and engaged on online films/games, tended to perform better than students spending a lot of time on entertainment-oriented unsupervised activities. Nevertheless, a few limitations should be acknowledged. First, as with all correlation data, no conclusion can be drawn about causality. For example, the relationship between time spent on reading and reading achievement might be bidirectional. In addition, any number of third variables, such as socioeconomic factors, might play an important role in both time use and reading achievement. Second, our findings based on data collected from the sample of Northern Taiwan may not be widely generalizable. Even so, this study has further developed the portfolio approach in the study of out-of-school time use and has provided a basis for a promising new course of research in this field.

\section{References}

Allen, L., Cipielewski, J., \& Stanovich, K. E. (1992). Multiple indicators of children's reading habits and attitudes: Construct validity and cognitive correlates. Journal of Educational Psychology, 84(4), 489-503.

Anderson, R. C., Wilson, P. T., \& Fielding, L. G. (1988). Growth in reading and how children spend their time outside of school. Reading Research Quarterly, 23(3), 285-303.

Bae, S., Oh, H., Kim, H., Lee, C., \& Oh, B. (2010). The impact of after-school programs on educational equality and private tutoring expenses. Asia Pacific Education Review, 11(3), 349-361.

Ben-Arieh, A., \& Ofir, A. (2002). Time for (more) time-use studies: Studying the daily activities of children. Childhood, 9(2), 225-248.

Bray, M. (2014). The impact of shadow education on student academic achievement: Why the research is inconclusive and what can be done about it. Asia Pacific Education Review, 15(3), 381-389.

Chen, S. Y., \& Fang, S. P. (2013). Developing a Chinese version of an author recognition test for college students in Taiwan. Journal of Research in Reading. doi: 10.1111/1467-9817.12018

Chen, S. Y., \& Fang, S. P. (2014, May 9-12). Assessing exposure to print: Development of measures for Taiwanese fifth graders. Paper presented at The International Reading Association Annual (IRA) Conference, New Orleans, U.S..

Chen, S. Y., \& Fu, Y. C. (2009). Internet use and academic achievement: Gender differences in early adolescence. Adolescence, 44(176), 797-812.

Chen, S. Y., \& Lu, L. (2009). After-school time use in Taiwan: Effects on education achievement and well-being. Adolescence, 44(176), 891-909.

Cooper, H., Robinson, J. C., \& Patall, E. A. (2006). Does homework improve academic achievement? A synthesis of research, 1987-2003. Review of Educational Research, 76(1), 1-62.

Cooper, H., Valentine, J. C., Nye, B., \& Lindsay, J. J. (1999). Relationships between five after-school activities and academic achievement. Journal of Educational Psychology, 91(2), 369-378.

Hung, L. Y., Wang, C. C., Chang, Y. W., Chen, H. F., \& Chen, Q. S. (2006). Size of Chinese characters test for elementary and junior high school students. Taipei: Ministry of Education in Taiwan.

Ko, H. W., \& Zhan, Y. L. (2006). Reading comprehension test for elementary school students. Taipei: Ministry of Education in Taiwan.

Kuh, G. D., Hu, S., \& Vesper, N. (2000). “They shall be known by what they do”: An activities-based typology of college students. Journal of College Student Development, 41(2), 228-244.

Kwok, P. (2004). Examination-oriented knowledge and value transformation in East Asian after-school private programss. Asia Pacific Education Review, 5(1), 64-75.

Larson, R. W., \& Verma, S. (1999). How children and adolescents spend time across the world: Work, play, and developmental opportunities. Psychological Bulletin, 125(6), 701-736.

Lee, A. I., Yang, C. N., \& Lin, C. Y. (2012). Evaluation of children's after-school programs in Taiwan: FAHP approach. Asia Pacific Education Review, 13(2), 347-357.

Lee, Y. H., \& Wu, J. Y. (2012). The effect of individual differences in the inner and outer states of ICT on engagement in online reading activities and PISA 2009 reading literacy: Exploring the relationship between the old and new reading literacy. Learning and Individual Differences, 22(3), 336-342. 
Leu, D. J., Kinzer, C. K., Coiro, J. L., \& Cammack, D. W. (2004). Toward a theory of new literacies emerging from the Internet and other information and communication technologies. In R. B. Ruddell, \& N. J. Unrau (Eds.), Theoretical models and processes of reading (pp. 1570-1613). Newark, D.E.: International Reading Association.

Mol, S. E., \& Bus, A. G. (2011). To read or not to read: A meta-analysis of print exposure from infancy to early adulthood. Psychological Bulletin, 137(2), 267-296.

Nelson, I. A., \& Gastic, B. (2009). Street ball, swim team and the sour cream machine: A cluster analysis of out of school time participation profolios. Journal of Youth and Adolescence, 38, 1172-1186.

Schreiber, J. B., \& Chambers, E. A. (2002). After-school pursuits, ethnicity, and achievement for 8th- and 10th- grade students. The Journal of Educational Research, 96(2), 90-100.

Song, K. O., Park, H. J., \& Sang, K. A. (2013). A cross-national analysis of the student- and school- level factors affecting the demand for private tutoring. Asia Pacific Education Review, 14(2), 125-139.

Stevenson, H. W., Lee, S. Y., Chen, C., Stigler, J. W., Hsu, C. C., Kitamura, S., \& Hatano, G. (1990). Contexts of achievement: A study of American, Chinese, and Japanese children. Monographs of the Society for Research in Child Development, 55(1/2).

Trautwein, U. (2007). The homework-achievement relation reconsidered: Differentiating homework time, homework frequency, and homework effort. Learning and Instruction, 17(3), 372-388.

Tse, S. (2014). To what extent does Hong Kong primary school students' Chinese reading comprehension benefit from after-school private tuition? Asia Pacific Education Review, 15(2), 283-297.

Wang, C. C., Hung, L. Y., Chang, Y. W., \& Chen, H. F. (2008). Number of characters school students know from Grade 1 to G9. Bulletin of Educational Psychology, 39(4), 555-568.

Zick, C. D. (2010). The shifting balance of adolescent time use. Youth \& Society, 41(4), 569-596. 